\title{
Orientierungshilfen im Buch
}

Das deutsche Gesundheitssystem ist ausgesprochen facettenreich und komplex - in seinem Aufbau und in seinen Funktionen. Das spiegelt sich auch in diesem Buch wider.

Um der Materie und der Fragestellung gerecht zu werden, haben wir verschiedene Orientierungshilfen eingebaut. Zur Kennzeichnung der Bedeutung unterschiedlicher Textpassagen gibt es verschiedene Kästchen. Bei der Ableitung der Regeln bewegen wir uns zwischen den fünf Ebenen von unten nach oben (Kap.4) und bei der Implementierung von oben nach unten (Kap.6). Zur leichteren Orientierung sind die entsprechenden Stellen durch verschiedene Icons am Seitenrand gekennzeichnet.

Die Orientierungshilfen im Einzelnen:

\section{Wichtige Aussagen}

\section{Wichtige Aussagen sind fett gedruckt.}

\section{Lesehinweise}

Lesehinweise erläutern das Vorgehen im folgenden Kapitel oder den folgenden Abschnitten oder geben kurze Zusammenfassungen. Das folgende Beispiel findet sich vor Kap. 4, in dem die Regeln abgeleitet werden.

Lesehinweise für das gesamte Buch:

\section{Lesehinweis}

1. Dieses Buch behandelt unser Gesundheitssystem als Ganzes. Es ist durch zahlreiche textliche Bezüge zwischen ganz unterschiedlichen Fachrichtungen und Themen gekennzeichnet. Um die technische Lesbarkeit zu vereinfachen, verwenden wir durchgängig das generische Maskulinum. 2. Wir betrachten das Gesundheitssystem aus ganz unterschiedlichen Sichtweisen. Zur Verbesserung der Verständlichkeit und Betonung wichtiger Aussagen setzen wir bewusst Redundanzen ein. Wir bitten um Ihr Verständnis. 


\section{Icons zur Orientierung}

\section{Icons in Kapitel 4}

In Kap. 4 leiten wir die Regeln ab und bewegen uns dabei von der untersten Ebene (Nr. 5) nach oben (Bottom-up). Zur Kennzeichnung der Systemebene, in der man sich gerade befindet, findet man am Seitenrand jeweils eine rote Ellipse als Icon.

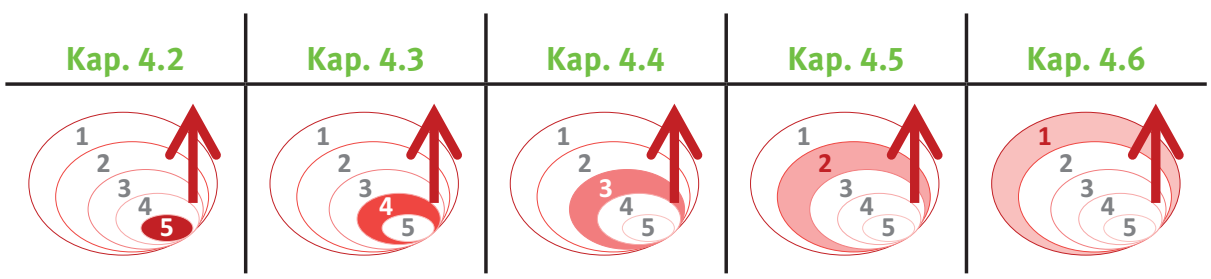

Der Pfeil nach oben weist darauf hin, dass man sich im Bottom-Up-Prozess (Kap. 4) befindet.

Die Regeln werden in der dritten Dezimalebene von 4.2.1 bis 4.6.3 dargestellt. Zur rascheren Übersicht findet sich am Rande ein grünes Ausrufezeichen als Icon. Der Text der jeweiligen Regeln findet sich in der Überschrift selbst.

\section{Icons in Kapitel 6}

In Kap. 6 implementieren wir die Regeln in das Referenzsystem und bewegen uns dabei von der obersten Ebene (Nr. 1) nach unten (Top-down). Zur Kennzeichnung der Systemebene, in der man sich gerade befindet, findet man am Seitenrand jeweils eine rote Pyramide als Icon.

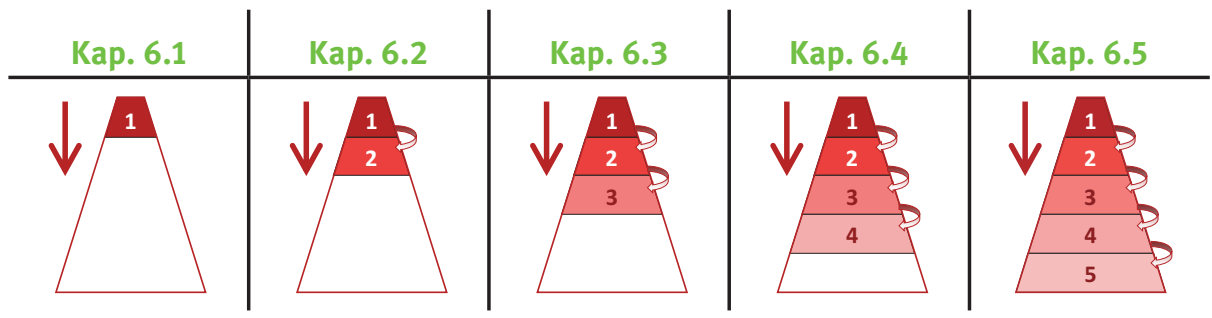

Der Pfeil nach unten weist darauf hin, dass man sich im Top-down-Prozess befindet.

G1 Entsprechend Kap. 4 werden die Regeln in der dritten Dezimalebene von 6.1.1 bis 6.5.3 dargestellt. Am Ende des Überschrifttextes findet sich der Name der Regel in Klammern z. B. (G1). Am Rand neben der Regel findet sich dieser Name mit rotem Text auf gelbem Hintegrund als Icon. Dieses Icon findet sich auch in den Abb. 6.4 bis 6.16 wieder. Dort kennzeichnen sie jeweils Stellen, an denen die Regel wirksam wird. 


\section{Hinweiskåsten für Textpassagen \\ In diesem Buch verwenden wir zur leichteren Orientierung verschiedene Kästen:}

\section{Kernbotschaften}

\section{STRATEGIEWECHSEL JETZT!}

\section{Hinweise zu Regeln oder zum Vorgehen insgesamt}

Hinweise zu einzelnen Regeln oder Regeln in der jeweiligen Ebene sind ebenso hervorgehoben wie Anmerkungen zu unserem methodischen Ansatz und Vorgehen in Bezug auf den Strategiewechsel insgesamt.

\section{Hinweise zum Inhalt oder zum Vorgehen im Kapitel}

Am Kapitelanfang finden sich gelegentlich Hinweise zum Inhalt des Kapitels oder zum logischen Vorgehen. 
